\title{
Management of hypertension in pregnancy
}

\section{Amanda Beech \\ Endocrinologist and \\ Obstetric physician, Royal \\ Hospital for Women, \\ Sydney}

\section{George Mangos}

Nephrologist and Associate professor of Medicine,

St George and Sutherland

Clinical School, St George

Hospital, UNSW Sydney

\section{Keywords}

antihypertensive

drugs, blood pressure,

hypertension, pre-

eclampsia, pregnancy

Aust Prescr 2021;44:148-52

https://doi.org/10.18773/ austprescr.2021.039

\section{SUMMARY}

Hypertensive disorders of pregnancy are common and can result in maternal and fetal morbidity and mortality. Women may have chronic hypertension, or develop hypertension during pregnancy.

Management involves close maternal and fetal surveillance. If an antihypertensive drug is needed, prescribe one that is safe in pregnancy.

Pre-eclampsia is a hypertensive disorder of pregnancy. Women at high risk of pre-eclampsia should start aspirin $150 \mathrm{mg}$ daily at 12-16 weeks gestation and continue until 36 weeks gestation, to reduce the risk of preterm delivery.

There are long-term cardiovascular and mortality risks associated with pregnancies complicated by gestational hypertension and pre-eclampsia. Ongoing cardiovascular and metabolic risk surveillance should be undertaken by the woman's general practitioner.

\section{Introduction}

In a normal pregnancy, blood pressure falls in the first trimester. The fall reaches a maximum of 10-15 mmHg (systolic) in mid-pregnancy, and returns to pre-pregnancy levels by term. Hypertensive disorders of pregnancy affect approximately 5-10\% of pregnancies in Australia. These disorders are associated with both maternal and fetal morbidity and mortality.

\section{Hypertension}

Hypertension is defined as a systolic blood pressure $140 \mathrm{mmHg}$ or above, or diastolic blood pressure $90 \mathrm{mmHg}$ or above. This should be confirmed over four hours with repeated measures, or after overnight rest, to determine if there is true hypertension. Severe hypertension is classified as a systolic blood pressure $160 \mathrm{mmHg}$ or above, or a diastolic blood pressure $110 \mathrm{mmHg}$ or above. Severe hypertension (160/110 $\mathrm{mmHg}$ or above) requires urgent management in hospital.

Hypertensive disorders of pregnancy can be divided into four categories:

- chronic hypertension

- primary

- secondary

- gestational hypertension

- pre-eclampsia and eclampsia

- $\quad$ pre-eclampsia superimposed on chronic hypertension.

\section{Chronic hypertension}

Chronic hypertension predates the pregnancy or is first diagnosed before 20 weeks gestation. It includes both primary hypertension and less commonly secondary hypertension, related to an underlying cause, such as kidney disease. Routine testing for secondary causes is not recommended in pregnancy, but should be considered postpartum. For pregnant women with chronic hypertension, the initial recommended tests are: ${ }^{1-3}$

- full blood count

- urea, creatinine and electrolytes

- liver function tests

- uric acid

- $\quad$ urinalysis and microscopy

- $\quad$ urine protein:creatinine ratio (to establish a baseline)

- $\quad$ ECG.

Chronic hypertension is associated with adverse maternal and fetal outcomes:

- $\quad$ superimposed pre-eclampsia-25\%

- $\quad$ preterm delivery - $28 \%$

- fetal growth restriction - $17 \%$

- $\quad$ perinatal death $-4 \%{ }^{4}$

Some women have white-coat hypertension. This is defined as a clinic blood pressure of at least $140 / 90 \mathrm{mmHg}$, but with normal blood pressure outside the clinic. It is diagnosed by 24 -hour 
ambulatory blood pressure monitoring or home blood pressure monitoring. White-coat hypertension is not entirely benign and is associated with an increased risk of pre-eclampsia (8\%). ${ }^{5}$ Generally, treatment is not required if the clinic blood pressure is below $160 / 110 \mathrm{mmHg}$ and the out-of-office blood pressure remains normal.

\section{Management}

Women with chronic hypertension may be taking antihypertensive drugs before conception or conceive while taking them. Some of these drugs are contraindicated or not recommended in pregnancy (Table 1). ${ }^{6}$ Table 2 lists oral antihypertensive drugs that are safer in pregnancy. 2,6

The mainstay of management of chronic hypertension in pregnancy is regular maternal review and strict blood pressure control. Often the physiological fall in blood pressure in the first trimester will allow for a reduction or cessation of antihypertensive drug therapy.
Optimal management includes maintaining the blood pressure around 110-140/85 mmHg, regular assessment for the development of pre-eclampsia and close surveillance of fetal growth and wellbeing. Signs and symptoms suggestive of pre-eclampsia include headache, visual changes, epigastric or right upper quadrant pain and oedema (see Box). Assessment also includes careful blood pressure measurement, ideally using automated office or a liquid crystal sphygmomanometer, and testing for proteinuria. Home blood pressure monitoring may form part of this assessment. Proteinuria is defined as a spot urine protein:creatinine ratio above $30 \mathrm{mg} / \mathrm{mmol}$ or urine protein excretion above 300 mg/24 hours. Dipstick urinalysis (automated or visual) is most commonly used to screen for proteinuria, with a 'negative' or 'trace' result being normal. One plus (1+) or more on dipstick is sensitive, but inaccurate and should be further evaluated with a spot urine protein:creatinine ratio.

Table 1 Antihypertensive drugs to avoid in pregnancy

\begin{tabular}{|c|c|c|c|}
\hline Antihypertensive class & Advice & Potential adverse effects & Recommendation \\
\hline ACE inhibitors & Contraindicated & $\begin{array}{l}\text { Teratogenic in the second and third trimester resulting in } \\
\text { fetal anuria, oligohydramnios, hypocalvaria, intrauterine } \\
\text { growth restriction and patent ductus arteriosus, death }\end{array}$ & $\begin{array}{l}\text { Stop drug ideally before } \\
\text { conception or at diagnosis } \\
\text { of pregnancy }\end{array}$ \\
\hline Angiotensin receptor blockers & Contraindicated & $\begin{array}{l}\text { Teratogenic in the second and third trimesters, fetal } \\
\text { anuria, oligohydramnios, hypocalvaria, intrauterine growth } \\
\text { restriction, patent ductus arteriosus, death }\end{array}$ & $\begin{array}{l}\text { Stop drug ideally before } \\
\text { conception or at diagnosis } \\
\text { of pregnancy }\end{array}$ \\
\hline Diuretics & Avoid & $\begin{array}{l}\text { Maternal hypovolaemia, fetal hypoglycaemia, } \\
\text { thrombocytopenia, hyponatraemia and hypokalaemia }\end{array}$ & $\begin{array}{l}\text { Use an alternative } \\
\text { antihypertensive }\end{array}$ \\
\hline $\begin{array}{l}\text { Beta blockers (other than } \\
\text { labetalol) }\end{array}$ & Avoid & Fetal bradycardia, intrauterine growth restriction (atenolol) & $\begin{array}{l}\text { Use an alternative } \\
\text { antihypertensive }\end{array}$ \\
\hline $\begin{array}{l}\text { Calcium channel antagonists (other } \\
\text { than nifedipine and diltiazem) }\end{array}$ & Avoid & Maternal hypotension and fetal hypoxia & $\begin{array}{l}\text { Use an alternative } \\
\text { antihypertensive }\end{array}$ \\
\hline
\end{tabular}

\section{Table 2 Antihypertensive drugs that can be safely used in pregnancy}

\begin{tabular}{|c|c|c|c|}
\hline $\begin{array}{l}\text { Antihypertensive } \\
\text { drug* }\end{array}$ & Class/action & Dose & Adverse effects \\
\hline Labetalol & Beta blocker & 100 mg twice a day - 400 mg three times a day & Bradycardia, bronchospasm, headache \\
\hline $\begin{array}{l}\text { Nifedipine controlled } \\
\text { release }\end{array}$ & $\begin{array}{l}\text { Calcium channel } \\
\text { antagonist }\end{array}$ & 30 mg daily - 60 mg twice a day & $\begin{array}{l}\text { Headache (first-dose effect), flushing, } \\
\text { tachycardia, peripheral oedema }\end{array}$ \\
\hline Methyldopa & Central action & 250 mg twice a day - 750 mg three times a day & $\begin{array}{l}\text { Depression, dry mouth, sedation, rarely } \\
\text { haemolysis and hepatitis }\end{array}$ \\
\hline Hydralazine & Vasodilator & 25 mg three times a day - 50 mg three times a day & Flushing, headache, lupus-like syndrome \\
\hline Prazosin & Alpha blocker & $0.5 \mathrm{mg}$ twice a day - $5 \mathrm{mg}$ three times a day & Orthostatic hypotension \\
\hline
\end{tabular}

* Although oxprenolol is safe, it is no longer available in Australia. 


\section{Gestational hypertension}

Gestational hypertension is the development of hypertension at or after 20 weeks gestation, in the absence of other features of pre-eclampsia (see Box). Gestational hypertension is associated with an increased risk of developing pre-eclampsia (up to $25 \%$, depending on the gestation at presentation), as well as the future development of cardiovascular disease. ${ }^{1-3}$ Fetal growth restriction is not typically a feature of gestational hypertension.

\section{Management}

Regular blood pressure monitoring is necessary to ensure the blood pressure remains at $110-140 / 80-90 \mathrm{mmHg}$. There should be regular assessment for the development of pre-eclampsia and close surveillance of fetal growth and wellbeing. Once the blood pressure is controlled, gestational hypertension may continue to be managed with outpatient care, under close and regular review.

\section{Pre-eclampsia}

Pre-eclampsia is a complex multisystem disorder of pregnancy arising from abnormal placentation, resulting in an imbalance of angiogenic and anti-angiogenic factors, oxidative stress and immunological involvement. The maternal response to this is thought to involve systemic vascular endothelial

\section{Box Features of pre-eclampsia and eclampsia}

Renal

- proteinuria - spot urine protein:creatinine ratio $30 \mathrm{mg} / \mathrm{mmol}$ or more

- acute kidney injury with serum creatinine $>90$ micromol/L

- oliguria: $<80 \mathrm{~mL} / 4$ hours

Haematological

- thrombocytopenia - platelet count $<100,000 /$ microlitre

- haemolysis

- disseminated intravascular coagulation

Hepatic

- raised serum transaminases (alanine aminotransferase or aspartate aminotransferase $>40 \mathrm{IU} / \mathrm{L}$ )

- severe right upper quadrant or epigastric pain

Neurological

- eclamptic convulsion

- sustained clonus (hyperreflexia is commonly found and not diagnostic)

- severe headache

- visual disturbance - photopsia, scotomata, cortical blindness

- stroke

Pulmonary oedema

Uteroplacental dysfunction with fetal growth restriction, abnormality on doppler imaging of the umbilical artery, stillbirth dysfunction. Pre-eclampsia may be superimposed on chronic hypertension, or present as new onset hypertension, arising at or after 20 weeks gestation, with the presence of one or more of the typical clinical features (see Box). ${ }^{1,2}$

Risk factors for pre-eclampsia include maternal age, primiparity, previous pre-eclampsia, multiple gestation, prolonged interpregnancy interval and assisted reproduction therapies. Other factors are underlying renal disease or hypertension, antiphospholipid syndrome, systemic lupus erythematosus, diabetes and a maternal body mass index (BMI) above $30 \mathrm{~kg} / \mathrm{m}^{2}$.

Adverse maternal outcomes include eclampsia, stroke, multiorgan failure, major haemorrhage and death. Fetal complications of pre-eclampsia include growth restriction, preterm delivery, placental abruption and perinatal death.

\section{Management}

Whether pre-eclampsia is new onset or superimposed on chronic hypertension, a multidisciplinary approach optimises maternal and fetal outcomes as delivery is the only definitive cure. There is a balance between the welfare of the growing fetus and the ongoing risk of maternal complications. Management should occur at a specialist centre with the required protocols and expertise because inpatient care is usually required.

For severe hypertension urgent management is indicated and drugs are required to rapidly lower blood pressure (Table 3). An infusion of magnesium sulphate can be considered as it reduces the rate of seizure by $50 \%$ (Table 4 ). $^{?}$

\section{Prediction and prevention}

A number of options are available in the first trimester for predicting the risk of pre-eclampsia. These include using maternal blood pressure and risk factors or combined prediction models using additional tests of placental growth factor and doppler imaging of the uterine artery. These tests are readily available and consideration needs to be given to how they could be integrated into antenatal care. In Australia, however, the cost effectiveness of combined first trimester screening for pre-eclampsia has yet to be evaluated. Although there is no current method of preventing pre-eclampsia, aspirin is recommended for women considered to be at high risk because of maternal risk factors or by clinical prediction models. The ASPRE trial used combined first trimester screening and found a $62 \%$ reduction in preterm pre-eclampsia at less than 37 weeks gestation in women who took aspirin $150 \mathrm{mg}$ daily. ${ }^{8}$ Women at high risk require early obstetric review, because starting aspirin before 16 weeks is most effective. If started for pre-eclampsia prophylaxis, aspirin should be continued until 
Table 3 Urgent treatment of severe hypertension* in pregnancy

\begin{tabular}{lllll}
\hline Drug & Dose & Route & Onset of action & Adverse effects \\
\hline Hydralazine & $5-10 \mathrm{mg}$ & $\begin{array}{l}\text { Intravenous bolus repeated after } \\
20 \mathrm{~min} \text { if blood pressure remains } \\
>160 / 110 \mathrm{mmHg}\end{array}$ & $20 \mathrm{~min}$ & $\begin{array}{l}\text { Flushing, headache, nausea, } \\
\text { hypotension, tachycardia }\end{array}$ \\
\hline Labetalol & $20-80 \mathrm{mg}$ & $\begin{array}{l}\text { Intravenous bolus over } 2 \mathrm{~min}, \\
\text { repeat after } 10 \mathrm{~min} \text { if blood } \\
\text { pressure remains }>160 / 110 \mathrm{mmHg}\end{array}$ & $5 \mathrm{~min}$ & $\begin{array}{l}\text { Bradycardia, hypotension, } \\
\text { fetal bradycardia }\end{array}$ \\
\hline Labetalol & $200 \mathrm{mg}$ & Oral & $30-45 \mathrm{~min}$ & $\begin{array}{l}\text { Bradycardia, bronchospasm, } \\
\text { headache }\end{array}$ \\
\hline Nifedipine & $10 \mathrm{mg}$ & Oral & $30-45 \mathrm{~min}$ & Headache, flushing \\
\hline
\end{tabular}

* Severe hypertension is 160/110 mmHg or above.

+ This formulation is no longer available in Australia.

Table 4 Seizure prophylaxis and treatment of eclampsia

\begin{tabular}{|c|c|c|c|c|}
\hline Drug & Dose & Route & Onset of Action & Adverse effects \\
\hline $\begin{array}{l}\text { Magnesium } \\
\text { sulphate }\end{array}$ & $4 \mathrm{~g}$ & $\begin{array}{l}\text { Intravenous bolus over } \\
20 \text { min followed by } 1 \mathrm{~g} / \text { hour } \\
\text { infusion, typically continued } \\
\text { for } 24 \text { hours }\end{array}$ & $20 \min$ & $\begin{array}{l}\text { Flushing, respiratory depression } \\
\text { Caution in renal impairment as } \\
\text { magnesium is excreted renally } \\
\text { and toxicity may occur }\end{array}$ \\
\hline
\end{tabular}

36 weeks gestation. Aspirin reduces the risk of preterm birth, fetal growth restriction and fetal death, but may increase postpartum bleeding. ${ }^{9,10}$

Women with an inadequate dietary calcium intake may have an increased risk of pre-eclampsia. They should aim to achieve the recommended daily allowance (1000 mg daily) through diet or calcium supplementation to reduce the risk."

\section{Postpartum management}

After delivery, hypertension typically resolves within 12 weeks for women with gestational hypertension or pre-eclampsia. If this does not occur, consideration should be given to investigation for primary or secondary hypertension. Regular monitoring of blood pressure postnatally should occur, with down titration of antihypertensive drugs when the systolic blood pressure drops below $120 \mathrm{mmHg}$. For women with chronic hypertension, the decision to return to their usual antihypertensive treatment will depend on its compatibility with breastfeeding, and their future pregnancy plans. It would be reasonable to transition them back to their usual treatment early, provided they remain aware of the importance of review before future pregnancies to ensure it will be safe to use.

The antihypertensive drugs that are safe in pregnancy are also safe in breastfeeding. However, given that methyldopa is associated with a $30 \%$ risk of depression, it is usually stopped postpartum. ACE inhibitors, particularly enalapril, have very low concentrations in breast milk and are often used during lactation. Angiotensin receptor blockers are not recommended due to a lack of available safety information.

\section{Long-term implications}

Gestational hypertension and pre-eclampsia are associated with a two- to fourfold increase in the future risk of cardiovascular disease. Women may develop hypertension, stroke, diabetes, venous thromboembolic disease or chronic kidney disease. Cardiovascular events such as stroke may occur in middle age. Given these risks, and the cumulative risks associated with several pregnancies complicated by severe pre-eclampsia, or preterm delivery, preconception counselling before future pregnancies is recommended.

Women with a history of hypertension in pregnancy require indefinite follow-up. They are recommended to have annual reviews of blood pressure, fasting lipids and blood glucose. Counselling on a healthy lifestyle and diet, maintenance of an optimal BMI, smoking cessation and regular exercise are essential for optimising long-term health outcomes. ${ }^{12-14}<$

Conflicts of interest: none declared

\section{SELF-TEST} QUESTIONS

True or false?

1. Angiotensin receptor blockers should not be used during pregnancy and lactation.

2. Women at high risk of pre-eclampsia should avoid taking aspirin after the first trimester of pregnancy.

Answers on page 177 
<ustralian Prescriber

VOLUME 44 : NUMBER 5 : OCTOBER 2021

\section{REFERENCES}

1. Brown MA, Magee LA, Kenny LC, Karumanchi SA McCarthy FP, Saito S, et al.; International Society for the Study of Hypertension in Pregnancy (ISSHP). The hypertensive disorders of pregnancy: ISSHP classification, diagnosis \& management recommendations for international practice. Pregnancy Hypertens 2018;13:291-310. https://doi.org/10.1016/j.preghy.2018.05.004

2. Lowe SA, Bowyer L, Lust K, McMahon LP, Morton M, North RA, et al. SOMANZ guidelines for the management of hypertensive disorders of pregnancy 2014. Aust N Z J Obstet Gynaecol 2015;55:e1-29. https://doi.org/ 10.1111/ajo.12399

3. Gestational hypertension and preeclampsia. ACOG Practice Bulletin Summary, Number 222 Obstet Gynecol 2020;135:1492-5. https://doi.org/10.1097/ AOG.0000000000003892

4. Bramham K, Parnell B, Nelson-Piercy C, Seed PT, Poston L, Chappell LC. Chronic hypertension and pregnancy outcomes: systematic review and meta-analysis. BMJ 2014;348:g2301. https://doi.org/10.1136/bmj.g2301

5. Brown MA, Mangos G, Davis G, Homer C. The natural history of white coat hypertension during pregnancy. BJOG 2005;112:601-6. https://doi.org/10.1111/j.1471-0528.2004.00516.x

6. Briggs GG, Freeman RK. Drugs in pregnancy and lactation: a reference guide to fetal and neonatal risk. 10th edition. Philadelphia (PA): Lippincott Williams \& Wilkins; 2014.

7. The Magpie Trial Collaborative Group. Do women with pre-eclampsia, and their babies, benefit from magnesium sulphate? The Magpie Trial: a randomised placebo-controlled trial. Lancet 2002;359:1877-90. https://doi.org/10.1016/ S0140-6736(02)08778-0

8. Rolnik DL, Wright D, Poon LC, O'Gorman N, Syngelaki A, de Paco Matallana $C$, et al. Aspirin versus placebo in pregnancies at high risk for preterm preeclampsia. N Engl J Med 2017;377:613-22. https://doi.org/10.1056/ NEJMoa1704559
9. Duley L, Meher S, Hunter KE, Seidler AL, Askie LM. Antiplatelet agents for preventing pre-eclampsia and its complications. Cochrane Database Syst Rev 2019;2019:1465-858. https://doi.org/10.1002/14651858.CD004659.pub3

10. Hastie R, Tong S, Wikström AK, Sandström A, Hesselman S, Bergman L. Aspirin use during pregnancy and the risk of bleeding complications: a Swedish population-based cohort study. Am J Obstet Gynecol 2021;224:95.e1-12. https://doi.org/10.1016/j.ajog.2020.07.023

11. Hofmeyr GJ, Lawrie TA, Atallah AN, Torloni MR. Calcium supplementation during pregnancy for preventing hypertensive disorders and related problems. Cochrane Database Syst Rev 2018;10:CD001059. https://doi.org/10.1002/14651858.CD001059.pub5

12. Theilen LH, Fraser A, Hollingshaus MS, Schliep KC, Varner MW, Smith KR, et al. All-cause and cause-specific mortality after hypertensive disease of pregnancy. Obstet Gynecol 2016;128:238-44. https://doi.org/10.1097/ AOG.0000000000001534

13. Tooher J, Thornton C, Makris A, Ogle R, Kord A, Horvath J, et al. Hypertension in pregnancy and long-term cardiovascular mortality: a retrospective cohort study. Am J Obstet Gynecol 2016;214:722 e1-e6. https://doi.org/ 10.1016/j.ajog.2015.12.047

14. Bellamy L, Casas JP, Hingorani AD, Williams DJ. Preeclampsia and risk of cardiovascular disease and cancer in later life: systematic review and meta-analysis. BMJ 2007;335:974. https://doi.org/10.1136/bmj.39335.385301.BE 